\section{Fusion scientists}

\section{urged to support political campaigns}

Washington. In a new and apparently desperate tactic to protect science funding from budget cuts, supporters of fusion research have been advised to enclose cash payments with letters to their congressmen seeking support for the troubled fusion programme.

The suggestion comes in a newsletter published by Fusion Power Associates, the main Washington interest group backing the $\$ 360$ million-a-year magnetic fusion programme. In an article headed "Fusion's last chance", the newsletter urges members of the organization to write to their member of Congress. "Also, you should think about sending a contribution to your congressperson along with your letter," it says. "They appreciate support from their constituents, as it helps to compensate their campaign costs."

Congressional staff are sceptical whether such a tactic is likely to have a significant impact. Congressmen look to their districts primarily for votes, not money, says one, and take all personal letters from constituents seriously.

Also, it is illegal for congressmen to run their official business and their campaign fund-raising from the same office. But enforcement of this split is problematic. It may be illegal to record the fact that supporters of, say, fusion research have sent campaign money. But it is hard to believe that every congressman would loftily ignore a deluge of cheques from constituents interested in any single issue.

What frustrates friends of science in Congress, staff say, is the stubborn refusal of scientists as a group to engage in the political process at all, despite their almost total dependence on the public purse. Congressmen who devote great attention to science "never get a dime out of these folks," one staffer observed ruefully. Getting them to write letters, he added, "is like pulling teeth".

Steve Dean, president of Fusion Power Associates and author of the cash appeal, says the problem is that "scientists don't do this kind of thing and everyone else does". Suggesting sums of $\$ 20$ or $\$ \mathbf{5 0}$ as suitable for donation purposes, Dean says that scientists have already lost their longcherished image as being aloof from the unseemly scramble for public funds.

Other science lobby groups are sceptical of the value of such a raw connection between cash and ideas. "We'd never do a thing like that," said the head of public affairs of a major scientific society. "It may be time for scientists to do it, but it isn't the time for us to tell them to do it." C.M.

\title{
Manhattan physicists cleared by FBI inquiry
}

Washington. Four nuclear physicists accused of spying for the Soviet Union in a book written by the former Soviet spy Pavel Sudoplatov, and published last year, have been cleared by an official inquiry carried out by the US Federal Bureau of Investigation.

The FBI inquiry found no evidence that J. Robert Oppenheimer, Enrico Fermi, Leo Szilard or Niels Bohr (all of them now dead) had knowingly supplied information to the Soviet Union while engaged on the Manhattan Project to develop the US atomic bomb. The allegations were made by Sudoplatov in his book Special Tasks, and were based on alleged contacts between the physicists and Soviet agents working in the United States.

The Clinton administration is expected to release this week the results of the FBI investigation, which was carried out at the request of the President's Foreign Intelligence Advisory Board (PFIAB). The inquiry was instigated by Sidney Drell, who is deputy director of the Stanford Linear Accelerator Center (SLAC) in California and a member of PFIAB.

Details of the exact wording of the announcement, as well as the official auspices under which it will be made, were still being agreed on Monday. But plans to issue a statement were confirmed by Randy Deitering, head of the PFIAB staff.

Sources close to the FBI's inquiry say that it found "no evidence whatsoever" that any of the four physicists accused by Sudoplatov had "wittingly assisted the KGB" at any time. The original charges had caused widespread anger in the scientific community, and had led to a suggestion from the Federation of American Scientists that publishers should experiment with a form of peer review to avoid what it portrayed as an attempted character assassination of Oppenheimer and his fellow physicists.

The outcome of the FBI review was revealed by Drell to physicists attending a recent gathering at Cornell University held to celebrate Hans Bethe's sixtieth year at the university. Bethe, who won the Nobel prize in 1967 for work that he had carried out some 30 years earlier on the theory of nuclear reactions, was head of theoretical physics at Los Alamos at the time of the Manhattan Project.

Some physicists who attacked the Sudoplatov book when it was published at the beginning of last year claim that its allegations about atomic spies had already been thoroughly discredited, and privately question the value of the FBI probe. "It'll just give the book more publicity," says said.

But Drell insists that former colleagues and the families of the four physicists were entitled to see them officially exonerated, and says he is confident that this week's statement from the administration will accomplish that goal.
Colin Macilwain

\section{Letter from Einstein goes to auction}

London. A 60-year-old letter (right) from Albert Einstein to Sir Karl Popper, who died last year aged 92 , is expected to fetch between $£ 6,000$ and $£ 8,000$ when it goes on sale at Sotheby's in London next month.

In the letter, Einstein gives Popper a résumé of the celebrated imaginary experiment in which he casts doubt on the ability of quantum mechanics to give a complete description of physical reality. Einstein's proposed experiment would have invalidated one that Popper himself had suggested; Popper was said to have been "mortified", unaware that Einstein's views were not shared by many of his contemporaries.

The letter is part of a sale that includes Popper's complete 6,000volume working library, which filled every room in his home - including outhouses, hallways and even the garage. Due to take place on 19 May, it will be the first auction in modern times

\section{IMAGE UNAVAILABLE FOR COPYRIGHT REASONS}

of a major philosopher's library.

The working library itself will be kept intact and sold as a single lot for an estimated $£ 200,000$. The master copies of Popper's books, including The Open Society and its Enemies and The Logic of Scientific Discovery, will also be auctioned as a single lot, and are expected to fetch $£ 50,000$. 